\title{
Monitoring and Security of Fiber Optic Lines in Cloud Computing within the Operation of Remote Laboratories
}

\author{
https://doi.org/10.3991/ijoe.v17i09.20157 \\ Pavel Beňo $\left.{ }^{1}{ }^{\bowtie}\right)$, František Schauer ${ }^{2}$, Sandra Šprinková $^{1}$, Tomáš Komenda ${ }^{2}$ \\ ${ }^{1}$ Trnava University, Trnava, Slovakia \\ ${ }^{2}$ Tomas Bata University, Zlin, Czech Republic \\ pavel.beno@truni.sk
}

\begin{abstract}
In this article, we want to point out what security and monitoring of fiber optics are. By increasing the number of RLs and, of course, connecting several locations through FO, we were able to build a cloud solution with a high level of security. However, the distance between the Datacentres (DTCs) is often large and there are many pitfalls on the road associated with the operation of the optical path, so we were forced to find a suitable monitoring solution. The main problems described are the bending or kinking of the optical fiber as well as the need for monitoring the safety of the fiber at the lowest level. In this article, we will describe how we have dealt with this issue and we will also mention specific cases where our monitoring system was very useful for us. With the help of it, we eliminated problems faster than we could have done in a common situation while waiting for an Internet Service Provider (ISP), etc.
\end{abstract}

Keywords-remote laboratories, cloud computing, REMLABNET, fiber optic, security, monitoring

\section{Introduction}

Scientific disciplines and associated science and research are difficult disciplines. Employees in the field of education, science and research are facing a reduced budget for their work and lack of interest of students. The events have been even more impaired thanks to Covid-19 pandemics that prevented students access to laboratories and school premises. Here we can observe a negative effect that has the greatest impact on experimental laboratories that have the worst collision on student education and their scientific leadership. In such problems, laboratories with lower creation costs for us is an important milestone. As one possible solution, especially in the previous century, is building so-called remote laboratories (RLS) that can be used by many clients without access to hands-on laboratories. After a long time, we found out that the remote experiments were unsatisfactory for teachers and thus resulting to new remote experiments, such as extensive graphical support for virtual reality (VR) and a rich range of artificial intelligence (AI), etc. 
Let's describe how the structure of the remote laboratories that can be seen in Figure 1. On a given figure shows the laboratory equipment (right), interface for communication with a computer or server and camcorder. Following is the main communication computer (server), where data from the experiment is coded to a standard web page and distributed to a client (left).

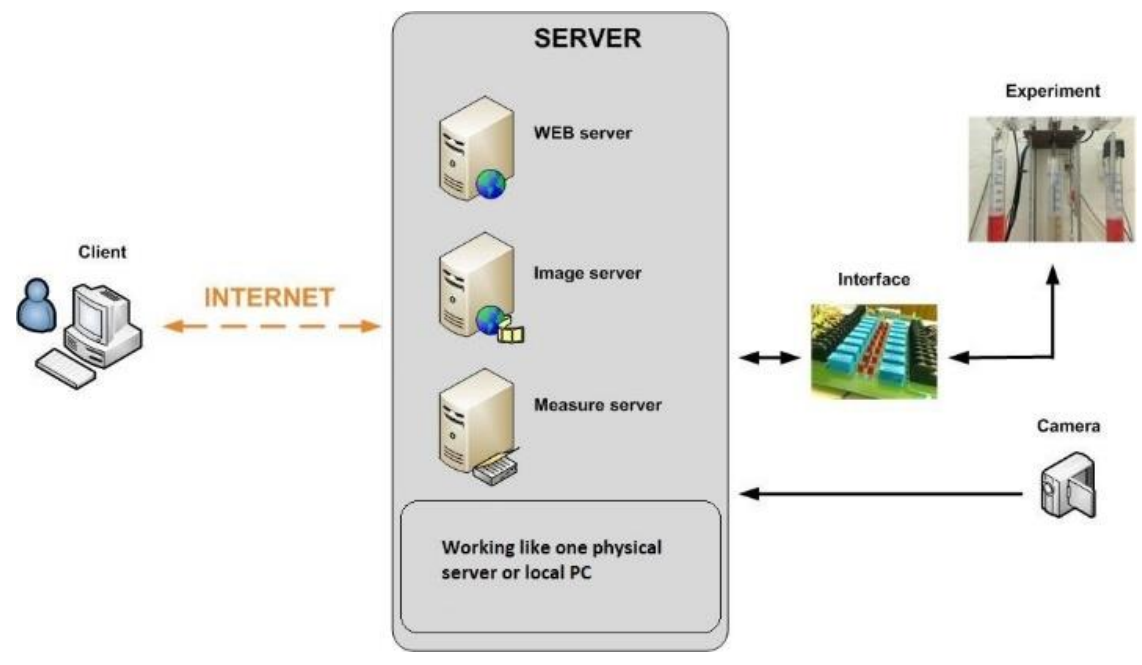

Fig. 1. Basic block diagram of Remote Laboratories [1]

The host of our laboratories is the Faculty of Applied Informatics (FAI) at Tomáš Bata University in Zlín and Trnava University in Trnava (here). Most of these laboratories are built on the Internet School Experimental System (ISES) [2], for example: Electrochemical Cell, Energy in RLC, Incline, Electromagnetic Induction, Radiation, Wave Laboratory, Described in [3,4,5 and 6]. All RLs are placed in the Remote Laboratory Management System (RLMS) REMLABNET, where they are supervised and monitored for functioning [7]. Some of the aforementioned RLs are equipped with embedded and synchronized simulations [8]. The block scheme of REMLABNET is depicted on Figure 2 with the following parts [9]:

- Data Warehouse (DW) - is a part of the system for storage and data analysis.

- Reservation and management server - part of the content management system (CMS) - generates a service enabling individual remote experiment reservation for a given time period.

- Communication server - next part of CMS is a system designed for the transmission of information and real-time communication, interaction and collaboration in teaching and learning process with RE.

- Virtualized cloud - Virtualized DTC contains physical and virtual servers which serve a variety of services including web services, file services etc.

- Additionally, the following servers were recently added:

- Diagnostic server - of I and II level [10],

- Embedded simulations server [11]. 
Further, embedded diagnostics that contains the first embedded diagnostics and the second embedded diagnostic are configured in the measurement server. When the experiment runs, it has a significant impact on the distant experiment. The embedded diagnostics communicate constantly with the physical ISES modules connected to the ISES control board. The diagram below shows the function and description of the embedded diagnostics in the Measure server [12]. Connection to Go-Lab served for federalization of two RLMS REMLABNET [13] and GO-LAB [14].

All of these REMLABNET components were placed in to the cloud of Trnava University in Trnava [15].

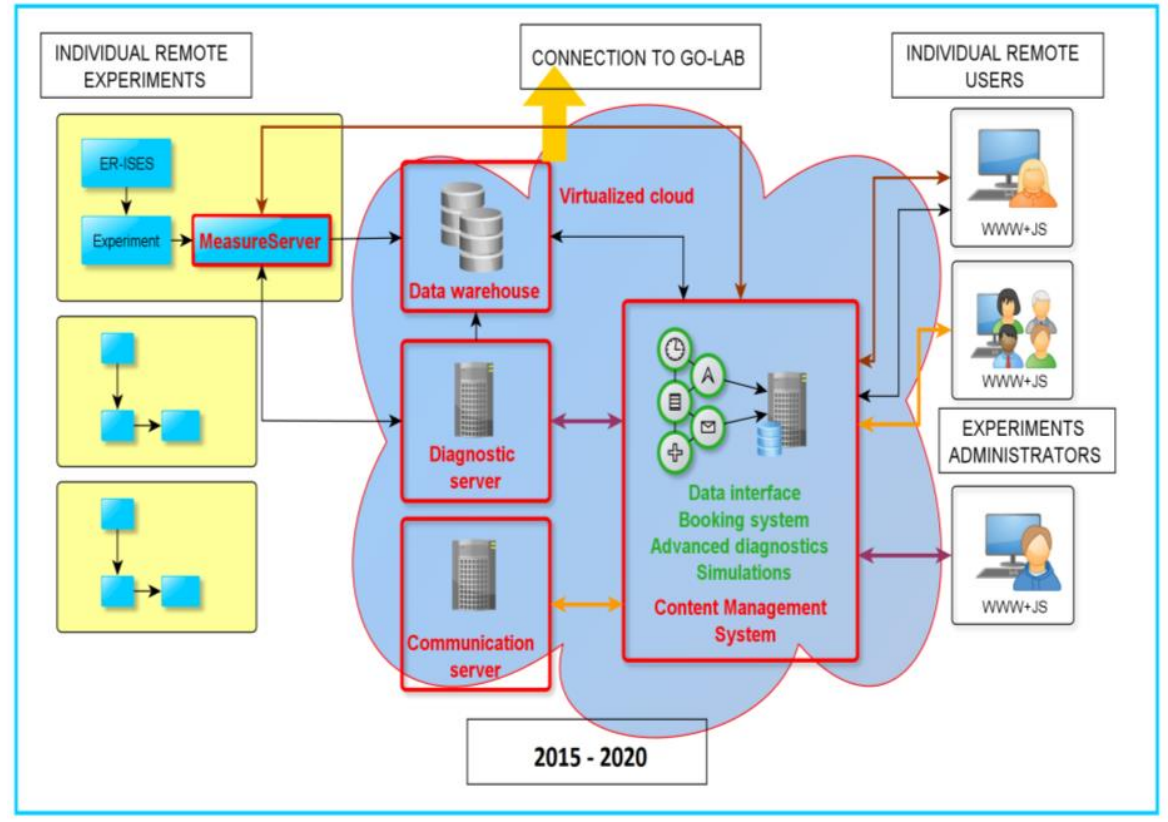

Fig. 2. Idea of the representation of the Remote Laboratory Management System REMLABNET schematically embedded in a virtualized cloud (shaded area). Note the "federalization" connection to the RLMS Go-Lab, also serving the Graasp interface [16]

DTCs are experiencing a huge rise in the last three decades and it has the consequences in virtually every domain application. Two trends have affected the transition to DTC. In parallel, functionality and data usually associated with personal computing have moved into the DTC; users continuously interact with remote sites whilst using local computers, while also running intrinsically online applications, such as email, chat or manipulating data. Traditionally these are stored locally, such as documents, spreadsheets, videos and photos.

In fact, modern architecture approaches virtualization and cloud computing (CC), a paradigm where the entire user activity is funnelled into large DTC through highspeed networks. Simply put, CC is a set of computers, services or infrastructure. De- 
livering services are meant to reduce the work of consumers every day, as well as service providers and IT specialists. CC allows more access to services as it reduces infrastructure delivery time from weeks to hours and it offers reimbursement for provided sources and services only [17].

Our main goal is to use new methods for providing RLS for client use. We can admit the primacy in the world to provide RLS through CC technology. This given concept is shown in Figure 3 where all remarkable parts of this idea are shown.

First, we can see the main parts of cloud computing. Each cloud is based on three primary services for use [18]:

IaaS - Infrastructure as a service is a standard service for providing all infrastructures;

PaaS - Platform as a service is a standard service for providing VMs with operating systems;

SaaS - Software as a service is a standard service for providing SW features for consumers.

Virtualized DTC contains physical and virtual servers, which serve a variety of services including web services, file services, etc. The advantages of DTC are enabling application isolation from malicious or greedy applications so that they cannot impact other applications co-located on the same physical server. Perhaps the biggest advantage of employing virtualization is the ability to flexibly remap physical resources to virtual servers in order to handle workload dynamics.

Our other aims are: To construct a really stable and dynamically expandable CC for using RLs. To create VMs and linkage for all parts in the cloud, it is necessary to create communication links, a virtual network for cloud computing inside, and all necessary parts for the Cloud computing concept. The goal of our work is the new and acute topic of providing a new service for consumers - a completely functioning "Remote laboratory as a service" (RLaaS) [19].

For this purpose, we created a Consortium named REMLABNET and this is a consortium of the three universities: Trnava University in Trnava (Slovakia), Tomas Bata University in Zlin (Czech Republic) and Charles University in Prague (Czech Republic). REMLABNET portal can be found at the domain name or web site www.remlabnet.eu [20].

In Figure 3 is the schematic arrangement of embedded REMLABNET, forming Cloud Computing REMLABNET (CC-R) in blocks. Block 1 (in Figure 3) represents the standard and known functions of REMLABNET, containing Remote Laboratories, Management and diagnostic service, Scheduling service and Communication services [09]. All these modules are controlled by a Unified service portal, enabling access to REMLABNET by clients and administrators. In block 2, there are platform services, a computing service interface, software test, middleware and database. There are also modules ensuring the functioning of both REMLABNET and CC-R and basic resource service (BRS). These are platform DTCs, Servers, Storage devices, Network, Security devices, and Charging management, Service catalogue, Order management, Resource scheduling, Monitoring management, Cloud host, Cloud storage, Cloud network, Cloud security and Disaster recovery service. 


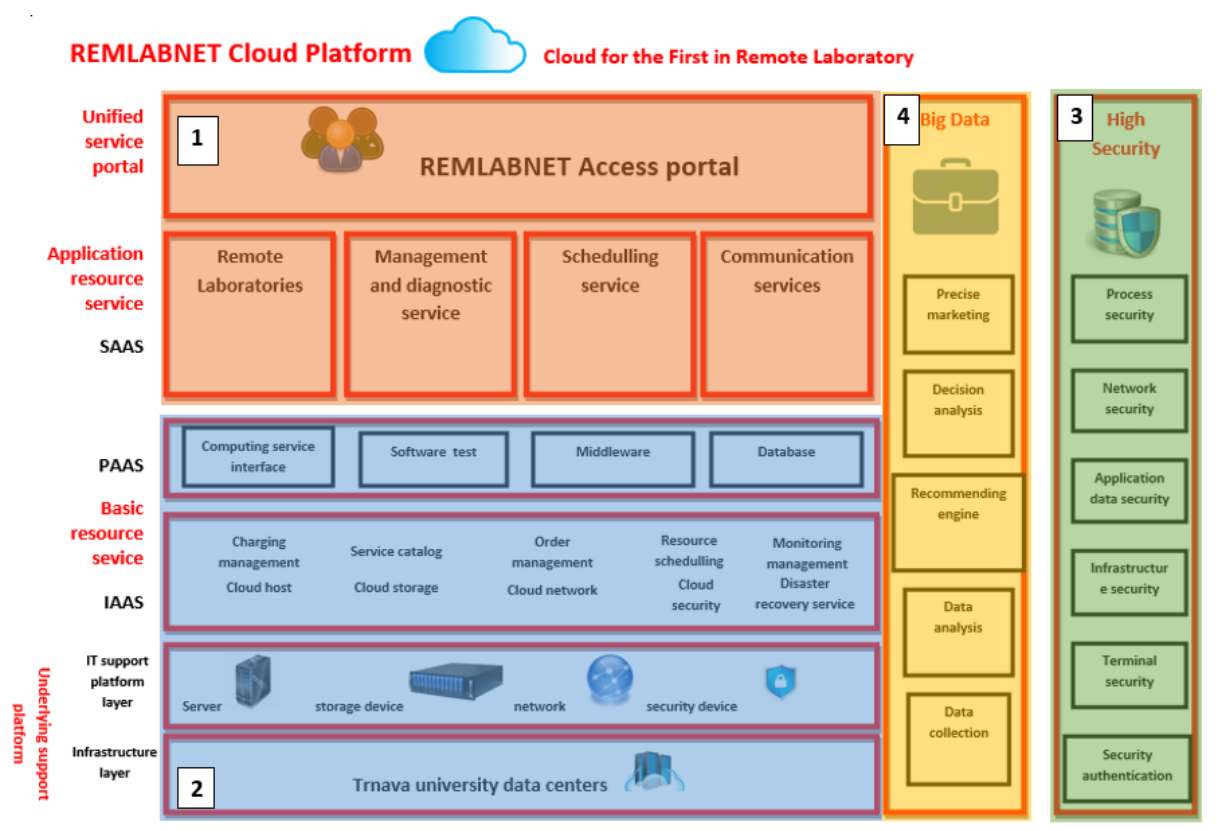

Fig. 3. Cloud computing concept in our Remote laboratory area

Two new blocks, called High Security (3) and Big Data (4) were supposed to be an extension of the basic cloud solution REMLABNET forming CC-R. Nowadays, only High Security is in operation. The second Big Data block is under construction. Block High Security (3) contains the most important security components [21], where we define our main processes that require special security protection. Process security in $\mathrm{CC}-\mathrm{R}$ is in fact the security of the individual RLs. Network security is managed from the University environment, but CC-R also uses the network settings above the University measures. Application data security assures security at the CC-R data level, their storage and individual accesses. Infrastructure security is a component securing the complete RLs CC-R portal, including its physical security. Terminal security is a component that ensures security on a thin client level. Security authentication is the last component, ensuring correct and secure access of clients and administrators.

\section{Monitoring communication}

Our CC service is located among two DTCs, which are geographically separate. First, let us show the general scheme of communication among individual DTCs using the example of DTCs in Trnava University, where our RLMS REMLABNET is embedded (Figure 4). Trnava University has three locally separated DTCs, connected via fiber optic connections. Network connectivity is designed on Cisco technology with security from the same company and an application firewall from the company 
Checkpoint. The university network is designed with respect to the organization structure of the University [16].

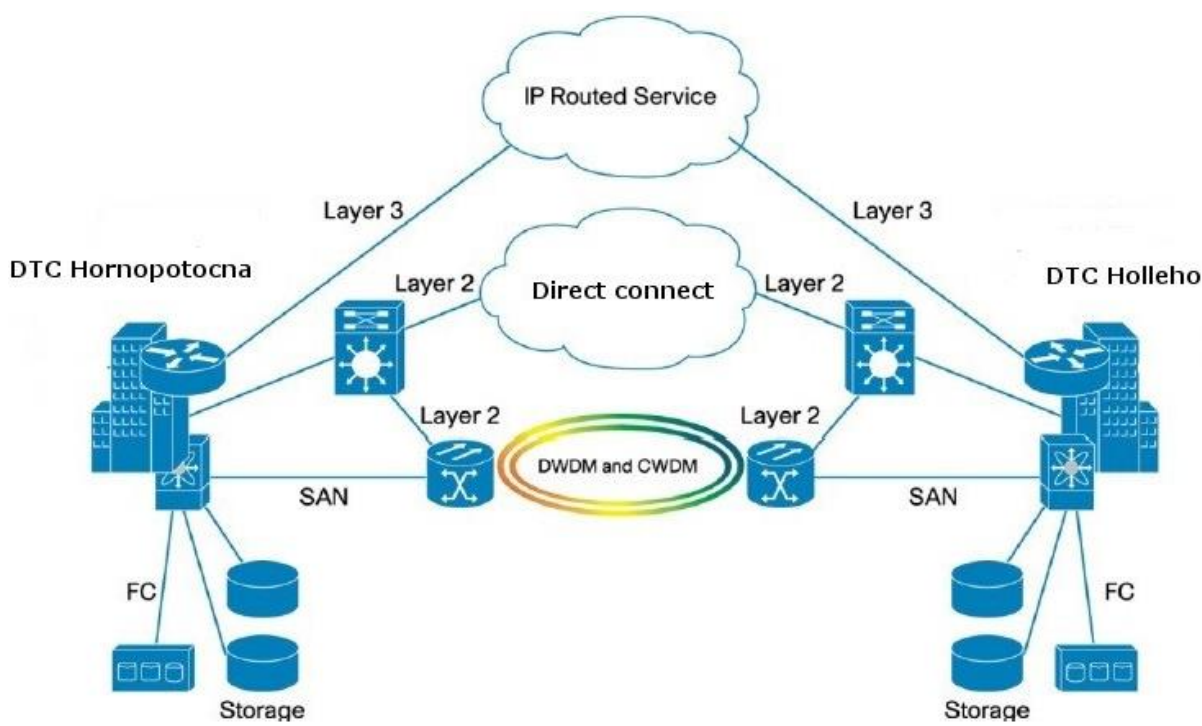

Fig. 4. Basic scheme of Trnava University network and DTCs

In our environment, we use single mode (SM) fiber made within the norm 652D: unshifted single mode optical fiber. What is most important for our work is shown in Figure 5, namely attenuation of the fiber optic in relation to the radius and wavelength used (bending loss). In Figure 5, we depict 3 possibilities of attenuation of the optical fiber within the radius of $10 \mathrm{~mm}, 15 \mathrm{~mm}, 20 \mathrm{~mm}$ and more on the frequency used. Within the frame of REMLABNET we use mostly the wave lengths $1310 \mathrm{~nm}, 1490 \mathrm{~nm}$ and $1550 \mathrm{~nm}$. The most common used are in particular Small Form-Factor Pluggable (SFP) transceiver with wave lengths $1310 \mathrm{~nm}$ and $1490 \mathrm{~nm}$, because we are also using them in passive Wavelength Division Multiplexing (WDM) technology between DTCs. This technique enables bidirectional communications over one strand of the fiber, as well as multiplication of its capacity.

First, let us show how Trnava University is using WDM technology (see Figure 4). This communication is set up between two data centres. The first is situated in Hornopotočná Street (the Rectorate of the University, Re) and the second is in Holleho Street (AdAlbertinum center, AA). Between these two individual DTCs is WDM, connected via Small Factor Pluggable (SFP) installed in Cisco Catalist 9400 (in Re) and 4507 (in AA). WDM uses four wavelengths. Two of them are used for standard communication between DTCs, one is used for phone lines, and the last one is used for Storage Area Network (SAN) connection between DTCs. SAN connection is very important, because this allows for a higher functionality in virtualization or cloud computing. This higher functionality is in the first-place migration of the VMs between host servers and storages in the DTCs. If we look at our system in Figure 2, 
these parts are not visible (all is one cloud) but they do constitute an important part of the whole communication system. Communication between DTCs should be very reliable, forming the backbone of the virtualized cloud and thus every system running within the cloud.

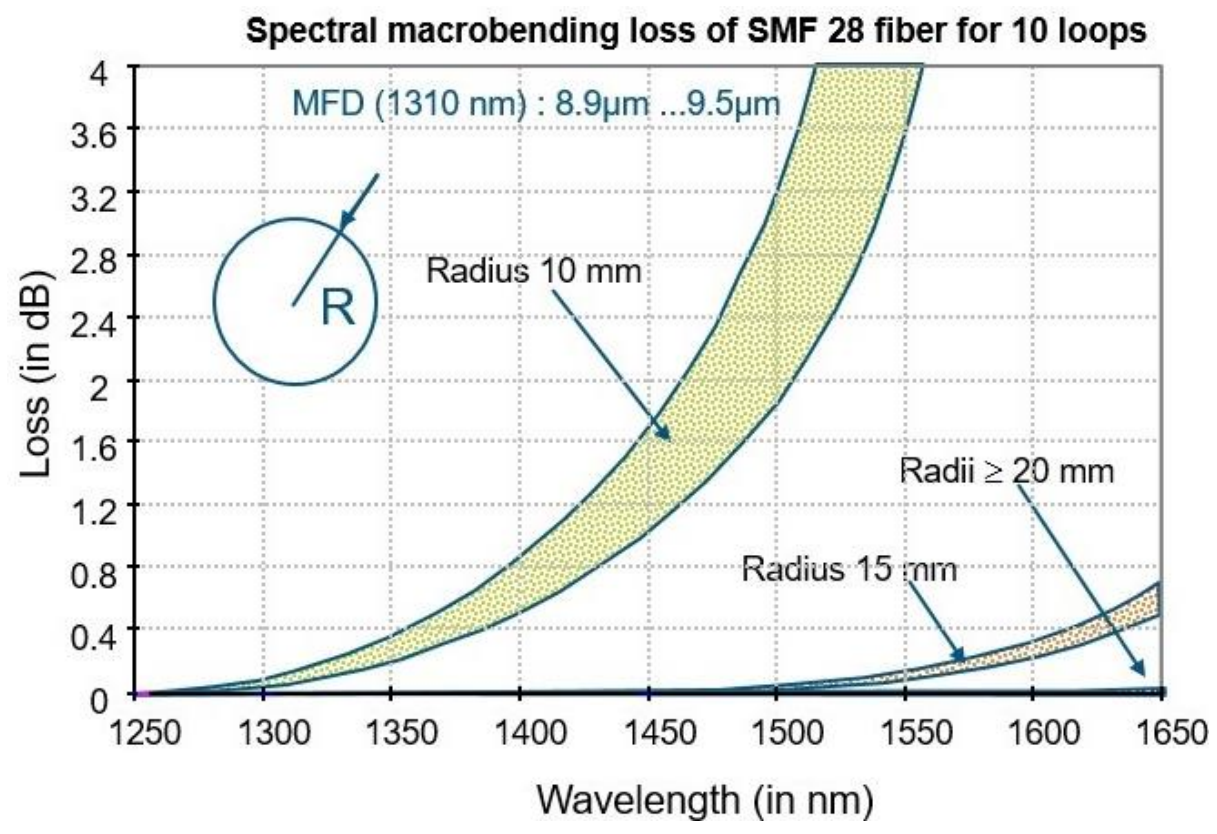

Fig. 5. Bending loss of performance of standard SM fiber (ITU-T G. 652D)

Let us return to fibers. Bending loss becomes important once the bending radius becomes smaller than $20 \mathrm{~mm}$. Measurements were made using 28 fiber cord with 10 loops in the cartridge. Our most commonly used wavelength, 1310nm, is the value of Mode field diameter (MFD) in scale from $8,9 \mu \mathrm{m}$ to $9,5 \mu \mathrm{m}$. MFD is important because, as a measure of the size of the optical field itself, it enables the design of launch-optics to match the mode of the source to that of the fiber and so maximize launching-efficiency.

\section{Methods for better security}

The main method of communication monitoring was accomplished with the help of four systems for measurement and evaluation of failure and attenuation:

- EXFO FTB 931 - this is a direct method for the measurement of attenuation change,

- EXFO FTB 200 + net blazer - for the measurement of transmission strength within the transmission lines, 
- MLS-50A - this is a permanent measurement of the network for attenuation and evaluation of fiber optic lines,

- Reflectometer DRB 200 + FT7300 - this is a distance measurement of the attenuation point on the transmission lines.

Failure measurements were a key point of our work with the cloud, because it was crucial for monitoring, finding, analyzing, evaluating and providing communication for the REMLABNET system. In Figure 6 it is schematically shown how the experiment was designed. After installation of CC-REMLABNET the communication was flawless, but after the installation of the REMLABNET we found enormous power cuts on the network interface between two DTCs, which subsequently caused instability in communication processes. Subsequently, communication dropouts (well observed in active parts and visible on CLI of the routers) were discovered. Thus, the problem was on the network level, and it constituted a significant problem. With hired instrumentation (EXFO FTB 200 + net blazer, producer EXFO) we started the measurement as shown in Figure 6a. We discovered that the attenuation of communication was on the level of $4.11 \mathrm{~dB}$ (Figure $6 \mathrm{~b}$ ), which is too much for communication bandwidth 1 Gbps FO fiber. With the help of FTB 200, we discovered a further problem with the SFP modules used, which were built for greater power (distance coverage). Then, in our configuration overload and the attenuation occurred, caused the excess attenuation. For checking the hypothesis we made the attenuator by ourselves from a patch cord. We simply wrapped the optical fiber in a coil, to create the attenuator. The hypothesis was affirmed, increasing the excess attenuation, the total attenuation of optical path had decreased to $1.11 \mathrm{~dB}$ (Figure 6c).

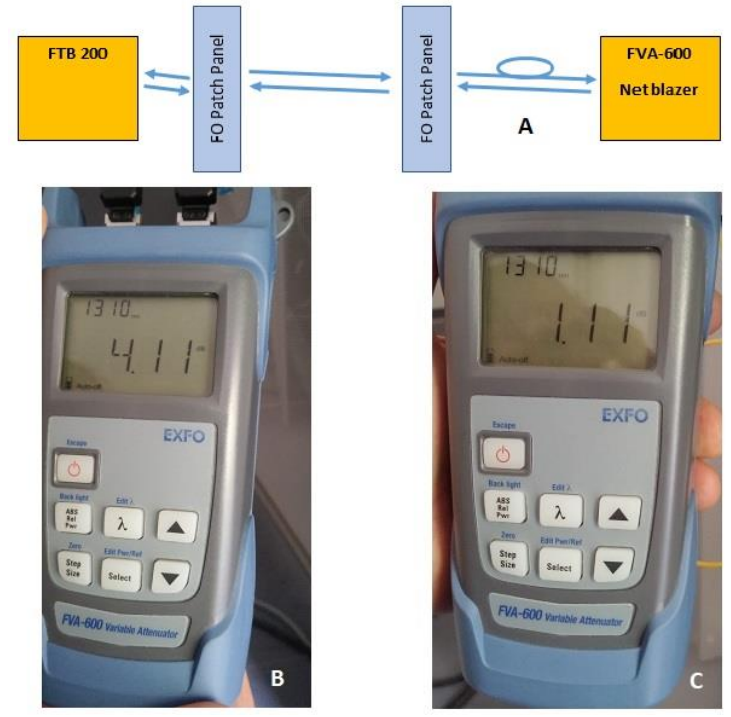

Fig. 6. Overload measurements of the SFP modules, a) arrangement of measurements with additional attenuator, b) attenuation measurements by EXFO FTB 200 without additional attenuation, c) the same as b) with additional attenuation. 
The next measurement was aimed at identification of security violation in the optical fiber between DTCs, which can be activated by mechanic effects, forced or unforced violation of fibers, or illegal monitoring of communication on optical fibers. For this reason, we introduced continuous monitoring - MLS-50A, the schematical arrangement of which can be seen in Figure 7. The setup consists of the couple transmitter-receiver of the optical signal for two cases: for communication with the wavelengths $1310 \mathrm{~nm}$ and $1550 \mathrm{~nm}$ and for monitoring 1550 and $1625 \mathrm{~nm}$. The functioning of the setup is as follows: let us suppose that the communication traffic is on $1310 \mathrm{~nm}$ between two DTCs. The Monitoring Line System (MLS) server sends measured impulses on $1550 \mathrm{~nm}$ through Wavelength Division Multiplexing (WDM), where the signal is connected to other communication and both wavelengths (1310 and 1550 $\mathrm{nm})$ travel together on one monitoring fiber. On the other side the WDM separates both signals again into communication and monitoring signals. The monitoring signal travels to the receiver MLS. Both Tx and Rx signals from MLS communicate via TCP protocol with the MLS server, which evaluates the power and delay of both (communication and monitoring) signals and may send info to the administrator's e-mail. Thus, monitoring is feasible even without the interruption of the fiber.

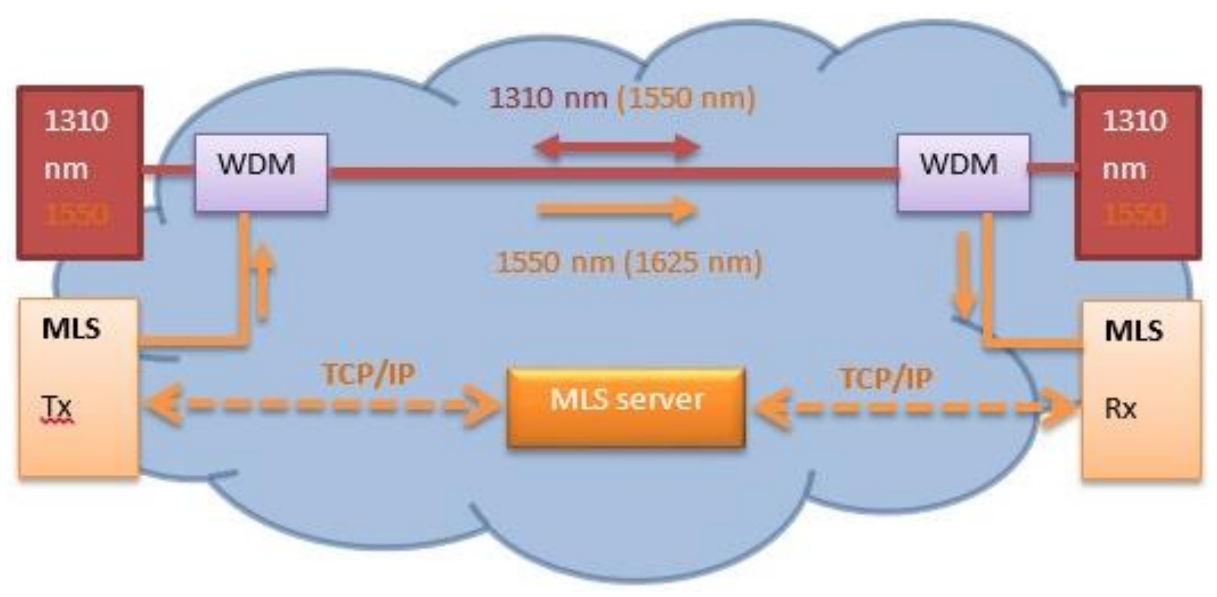

Fig. 7. Schematic arrangement of online delay and attenuation measurements on the optical network

The system MLS allows also the measurement of Transient Optical Loss (TOL), which may occur during full traffic and usually reports about a more serious damage on the transition line. This is the reason it was monitored during full traffic and continuously reported on. The result of our example measurements of TOL (with a duration of $0.2 \mathrm{~s}$ ) is in Figure 8, where significant loss of packets at the level of $3 \mathrm{~dB}$ is followed by the residual loss of about $0.5 \mathrm{~dB}$. 


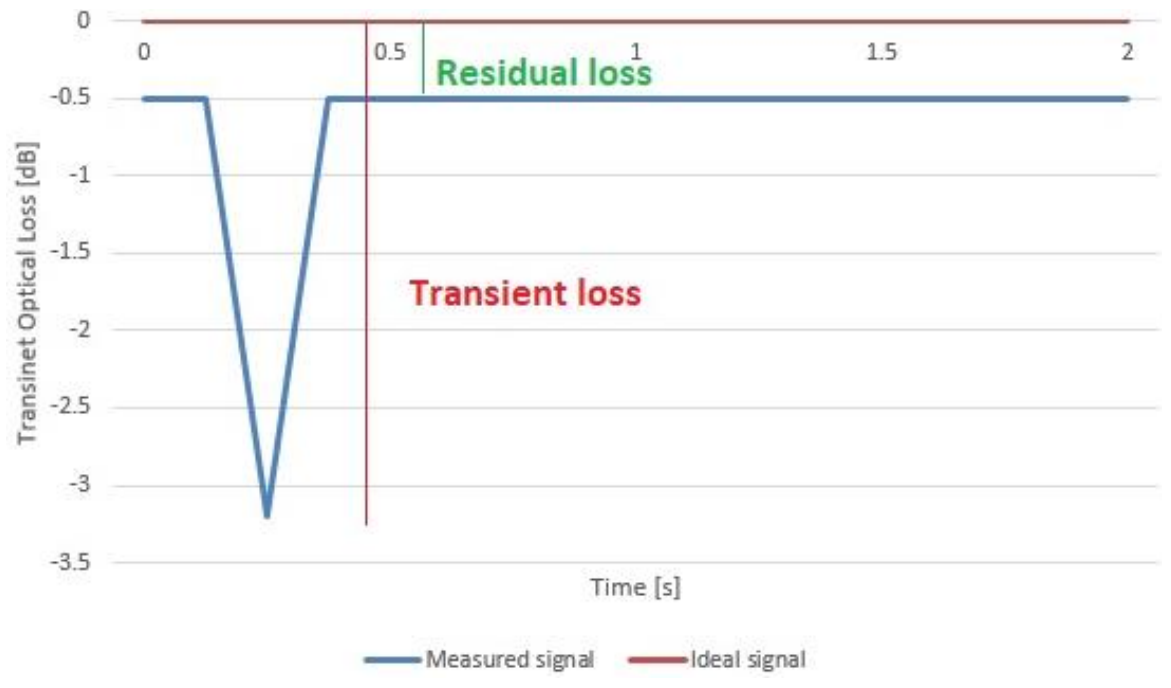

Fig. 8. Example of transient optical loss between two DTCs

For illustration, the instrumentation sources of TOL for individual bit errors are gathered in Table 1.

Table 1. Transient loss vs. bit errors

\begin{tabular}{|l|c|c|}
\hline $\begin{array}{c}\text { Transient loss } \\
(\mathbf{d B})\end{array}$ & Bit error & Note \\
\hline 0.6 & B1 & $\begin{array}{c}\text { Differences indicate the occur- } \\
\text { rence of section-level bit errors }\end{array}$ \\
\hline 1 & B1+B2 & $\begin{array}{c}\text { Differences indicate the occur- } \\
\text { rence of line-level bit errors. }\end{array}$ \\
\hline 3.5 & B1+B2+B3 & $\begin{array}{c}\text { Differences indicate the occur- } \\
\text { rence of path-level bit errors. }\end{array}$ \\
\hline 4.5 & B1+B2+B3+ REI & Remote Error Identification \\
\hline 5 & B1+B2+B3+ REI+TIM & Trace Identifier Mismatch \\
\hline 5.5 & B1+B2+B3+REI+ TIM+ SYNC & Synchronization loss \\
\hline 6.5 & B1+B2+B3+ REI+ TIM+ SYNC+ OOF & Out of Frame \\
\hline 8 & B1+B2+B3+REI+ TIM+ SYNC+ OOF+ LOF & Loss of Frame \\
\hline 8.5 & B1+B2+B3+REI+TIM+SYNC+OOF+ LOF+ LOS & Loss of Signal \\
\hline
\end{tabular}

The measurement of TOL was important to discover excess attenuation caused during installation of the cloud, due to the bending of FO fiber. Then, based on the measured distance of error, we discover immediately the site of the accident, which could then be removed. The principle of the distance of fault finding is depicted in Figure 9. 


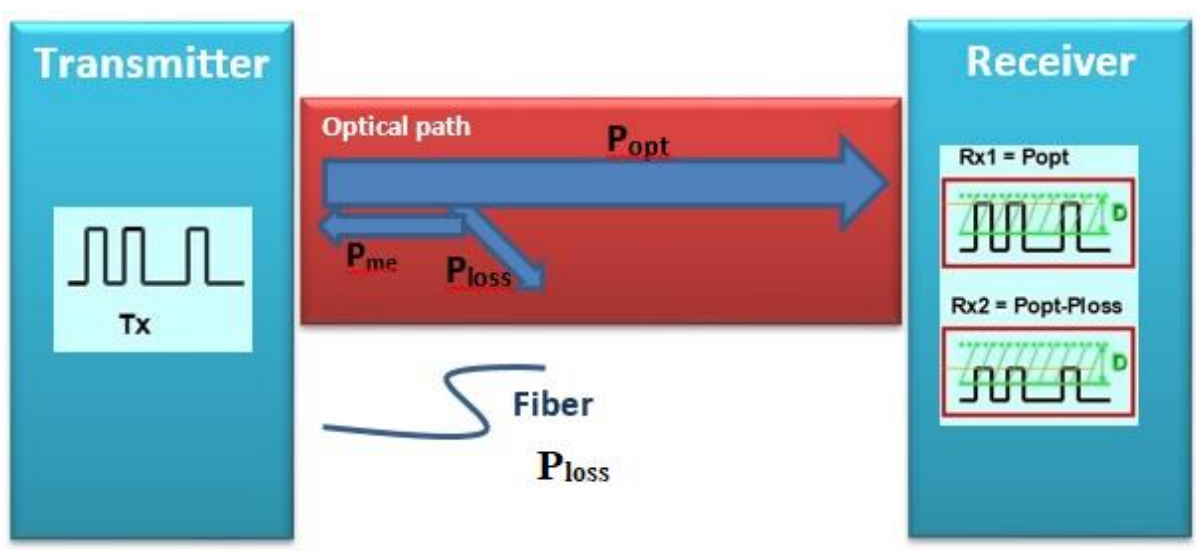

Fig. 9. Scheme of the measurement by MLS method of the source and position of the optical power attenuation

\section{Conclusions}

In this paper, we have attempted to point out the necessity and importance of things which are often overlooked. The link of cloud nodes frequently misses monitoring structures, on which it is built. This is commonly the cause of disruption or total malfunction of the whole system. In this work, we show the simple option of monitoring the optical fiber, which connects single nodes of a cloud. A simple bend of the patch cords can cause significant problems with attenuation and, of course, transmission speed in the reflection of light. This is why we want to further address the issue and gradually develop it. So far, we have introduced a relatively simple, inexpensive, but fully functional system for monitoring optical paths. We are already working on improving WDM solutions, which will make the all communication within the cloud clearer and, of course, faster. From the point of view of the cloud and its individual nodes, the speed and reliability of transmission is probably the primary requirement [for more information: 22].

\section{Acknowledgement}

The support of the Grant from the University of Trnava in Trnava No. 22/TU/2020 is acknowledged.

\section{References}

[1] Beňo P., Cloud computing solutions and security of EU remote interactive laboratories network. Tomas Bata University in Zlin, Zlín, 2019, pg. 142, ISBN 978-80-7454-884-0, Available at: http://hdl.handle.net/10563/45885. Tomas Bata University in Zlin, Faculty of 
Paper-Monitoring and Security of Fiber Optic Lines in Cloud Computing within the Operation...

Applied Informatics, Department of Electronics and Measurements. https://doi.org/10. 7441/joc. 2014.04.03

[2] Schauer, F., Kuřitka, I., Lustig, F.: Creative Laboratory Experiments for Basic Physics Using Computer Data Collection and Evaluation Exemplified on the Intelligent School Experimental System (ISES), Exploring Innovation in Education and Research, iCEER-2005, Taiwan, 1-5 March 2005.

[3] Schauer F., Krbeček M., Das S., Gerža M., ““"Electromagnetic Remote Laboratory” with Embedded Simulation and Diagnostics ", in International Conference on Remote Engineering and Virtual Instrumentation, 2019. https://doi.org/10.1007/978-3-319-95678-7_25

[4] Schauer F., Krbeček M., Das S., Ožvoldová M., Lustig F., "“"Radiation Remote Laboratory" with two level diagnostics ", in Smart Industry \& Smart Education, 2019. https://doi .org/10.1007/978-3-319-95678-7_36

[5] Schauer F., Krbeček M., Gerža M., Ožvoldová M.: ““'Remote Wave Laboratory” with Embedded Simulation - Real Environment for Waves Mastering “, in International Conference on Remote Engineering and Virtual Instrumentation, New York, 2017. https://doi. org/10.1007/978-3-319-64352-6_18

[6] Schauer F., Ožvoldová M.: "Remote Laboratories"in Research-based education of real world phenomena, U. o. D. S. Prof. Dr. Javier Garcia Zubia, Ed., Frankfurt: Peter Lang $\mathrm{GmbH}, 2014$.

[7] Schauer F., Krbeček M., Beňo P., Gerža M., Pálka L. and Špiláková P. "REMLABNET open remote laboratory management system for e-experiments" in REV 2014, Porto University, 26-28 February 2014. https://doi.org/10.1109/rev.2014.6784273

[8] Schauer F., Krbeček M., Beňo P., Gerža M., Pálka L., Špilakova P., Komenda T., Ožvoldová M., Gerhátová Ž and Tkáč L: "REMLABNET IV — LTI federated laboratory management system with embedded multiparameter simulations“. In 2017 14th International Conference on Remote Engineering and Virtual Instrumentation (REV). 15,-17 March 2017, Columbia University, New York, USA. Pg. 340-350. https://doi.org /10.1109/rev.2016.7444471

[9] SCHAUER, F. and col.: "REMLABNET II - open remote laboratory management system for university and secondary schools research based teaching". In 12th International Conference on Remote Engineering and Virtual Instrumentation (REV). 25-28 February 2015, Bangkok, Thailand, 978-1-4799-7838-0/15/\$31.00 @2015 IEEE. https://doi.org/10.1109/ rev.2015.7087273

[10] Schauer F., Krbeček, M.: "Communication and diagnostic interfaces in remote laboratory management systems"in International Journal of Online Engineering. Kassel University Press GmbH 2015. https://doi.org/10.3991/ijoe.v11i5.4926

[11] Schauer F., Gerža M.: "Intelligent processing of experimental data in ISES remote laboratory“ in International Journal of Online Engineering. Kassel University Press GmbH 2016. https://doi.org/10.3991/ijoe.v12i03.5538

[12] Gerža M., Schauer F.: "Advanced modules diagnostics in ISES remote laboratories"In 10th International Conference on Computer Science and Education, ICCSE 2015 [online]. Cambridge: Institute of Electrical and Electronics Engineers (IEEE), 2015, s. 583-589. https://doi.org/10.1109/iccse.2015.7250314

[13] Schauer F., Krbeček M., Beňo P., Gerža M., Pálka L., Špiláková P., "REMLABNET III — Federated remote laboratory management system for University and secondary schools" in 2016 13th International Conference on Remote Engineering and Virtual Instrumentation, REV 2016, Madrid, Spain, 24-26 February 2016, Auer M. E. et al., Eds. Madrid, Spain: IEEE, 2016, pg. 238-241, DOI: 10.1109/REV.2016.7444471, ISBN: 978-1-4673-8246-5, 
Paper-Monitoring and Security of Fiber Optic Lines in Cloud Computing within the Operation...

Available at: http://ieeexplore.ieee.org/lpdocs/epic03/wrapper.htm?arnumber=7444471, https://doi.org/10.1109/rev.2016.7444471

[14] GoLab, "GoLab," GoLab, [Online]. Available: http://www.go-labz.eu. [Accessed 299 2020].

[15] Beňo P.: "Cloud Computing concept for digital consumers"in SIT 2018 - International Scientific Days, 16.-17. May.2018, Nitra-Slovakia

[16] Beňo, P., Schauer, F.: "Remote laboratory management center REMLABNET embedded in University network - security and redundancy aspects"in The 6th International Virtual Scientific Conference on Informatics and Management Sciences, 26.-30. March 2017, eISSN: 1339-9144, cdISSN: 1339-231X, 10.18638/ictic.2017.6.1.312, ISBN: 978-80-5541325-9. https://doi.org/10.18638/ictic.2017.6.1.312

[17] Beňo, P., Schauer, F., Vlček, K.: "University network with Remlabnet and communication among individual datacenters"Varna, Bulgaria: IEEE Computer Society's Conference Publishing Services, 2014. ISBN 978-1-61804-246-0, pg. 240.

[18] Beňo P.: "University network with security aspects and redundancy to ISP"in SIT 2016 International Scientific Days, Nitra, Slovakia, 19.-20. May 2016, Horská E., Kapsdorferová Z., Hallová M., Eds. Nitra, Slovakia: Slovak University of Agriculture in Nitra, 2016, pg. 739-745. https://doi.org/10.24917/9788380840973.6

[19] Beňo P.: "NEW CONSUMER GENERATION WANT TO STAY ONLINE"in Marketing Identity - Offline is a new online, University of Ss. Cyril and Methodius in Trnava, Slovakia, 5.-6. November 2019, Kusá A., Zaušková A., Bučková Z., Eds., Trnava: Faculty of Mass Media Communication, University of Ss. Cyril and Methodius in Trnava, 2019, pg. 412-421. https://doi.org/10.18662/po/11.4/220

[20] MATARRITA, C. A., CONCARI, S. B.: "Remote laboratories used in physics teaching: a state of the art". In AUER M. E. et al. (ed.): 13th International Conference on Remote Engineering and Virtual Instrumentation (REV). Madrid, Spain: IEEE, 2016, p. 376-381. https://doi.org/10.1109/rev.2016.7444509

[21] Beňo P., Schauer F., Jašek R.: "Security and risks in Cloud Computing for remote laboratories" in ICTIC - PROCEEDINGS IN CONFERENCE OF INFORMATICS AND MANAGEMENT SCIENCES, vol.2, ICTIC 2013, Žilina, 25.-29. March 2013, Matiaška, K., Lieskovký, A., Mokryš, M., Eds. Žilina: EDIS - Publishing Institution of the University of Zilina, 2013, pg. 333-335.

[22] Beňo, P., Schauer, F. \& Šprinková, S., 2020. Increased importance of remote laboratories due to Covid-19. in AUER M. E. et al. (ed.): International Journal of Online Engineering, vol. 16, no. 12, Kassel University Press GmbH 2020. https://doi.org/10.3991/ijoe .$v 16 i 12.16699$

\section{$7 \quad$ Authors}

Pavel Beňo is currently working at Trnava University in Trnava, has a Ph.D. from the Faculty of Applied Informatics in Tomas Bata University in Zlín, Czech Republic, in the field of Remote Laboratories. He is a research assistant and creator of the cloud computing technology for university and REMLABNET purposes. He is also an expert in network security and penetration testing in computer crime. He is the author of many publications in the field of informatics, security and education. For many years he has worked as a teacher with research in pedagogy and didactics of the sciences. 
Paper-Monitoring and Security of Fiber Optic Lines in Cloud Computing within the Operation..

František Schauer received a M.S. degree in Electronics from the Brno University of Technology in 1963 and his Ph.D. in Solid State Physics from the Prague University of Technology in 1978. In 1982 he was appointed Associate Professor and in 1988 Professor in Condensed Matter Physics at the Technical Academy in Brno, Czech Republic. In 1993-2002 he was with the Faculty of Chemistry, Brno University of Technology and since then he was with the Polymer Centre of the Faculty of Technology. At present he is with the Tomas Bata University in Zlín, Faculty of Applied Informatics, Czech Republic. His main activities are molecular organic electronics, electronic structure spectroscopy by electrochemical and charge injection methods and computer assisted experiments. He is the author of about 300 papers in Solid state physics, Education practice and Remote laboratories with around 350 SCI citations.

Sandra Šprinková is currently studying for her bachelor's degree in the Pedagogical Faculty of Trnava University in Trnava in the field of Mathematics and English. She is working on the creation of a mathematical model for virtual laboratories that will be used in schools for better educational processes in the Sciences.

Tomas Komenda is a PhD student at Tomas Bata University in Zlín, Faculty of Applied Informatics, Czech Republic, and he is working in Seznam CZ company.

Article submitted 2020-11-30. Resubmitted 2021-07-10. Final acceptance 2021-07-13. Final version published as submitted by the authors. 